\title{
Education in the Age of Technology: Contrasting Fortunes
}

\author{
Saeed Ullah Jan \\ Department of Computer Science \& IT, University of Malakand, Chakdara, Pakistan
}

Email address:

saeedullah@uom.edu.pk

To cite this article:

Saeed Ullah Jan. Education in the Age of Technology: Contrasting Fortunes. Science Journal of Education. Vol. 6, No. 2, 2018 , pp. 55-70. doi: 10.11648/j.sjedu.20180602.13

Received: April 11, 2018; Accepted: April 27, 2018; Published: May 18, 2018

\begin{abstract}
Whatsoever the future, it will not be as visualized. The education development of 2018 is completely different from that of 1918, or of 1981, and imagining future situations is not consequently informal. The potential dreams become outof-date faster than estimated. No one can tie a fixed configuration of the future. And such a situation either progressive or toxic, depends on its position in the world, and as well as the geopolitical and multicultural aspect - which world occurred to have as all live. The world today is global, soft, cybernetic and polycentric. The change from traditional mass media to a system of straight communication networks, controlled around the world via the Internet and wireless communication has certainly brought a change that became the foundation of essential progressive revolution. This article briefly discusses the use of modern technological developments and the concept of globalization for learning. In the first part, a brief introduction of the learning is discussed; the second and third parts briefly touch different methods of learning. How these methods are used for the learning process by a tutor has also been presented and demonstrated in this article. The result in each section of the article shows that among numerous teaching and learning strategies, only four are recommended for each tutor and learner.
\end{abstract}

Keywords: Internet, 3D Hologram, Virtual Reality, Integrity, Globalization, Recursion, Skeleton, Stakeholder

\section{Introduction}

Each country, organization, or generation makes efforts in its own way for structuring education according to a set pattern. A lot of current books are concerned with the technology-oriented teaching or the so-called digital education insurgency, predominantly in coordination to the Internet, web-tools and the digital learning skills required by current learners [1-3]

The title of this paper suggested a similarly exciting volume of collective topics, all referenced and relevant to a developing social and technologically influenced community of $21^{\text {st }}$-century learners. The role of technology is an increasingly flexible tool for enhancing the learning environment and is an essential need for a modern knowledge-based society. The main theme of the study is highlighted in this part; existing literature works in the second part, while recommended methodology is discussed in some detail in the last portion of the study.

The prevalent idea does not in any sense conforms to the newer and challenging patterns; however it does focus upon the observations and concentrates on few arguments - counting population of learners, variation within the public affected by technology and its effect on learning domains, and the whole idea or justification of teaching and learning within education in the broadest sense. Previously, it was not categorically supported that the reading and consent of learning using technological intervention is supported by only technologically-passionate teachers. The reverse argument was then proposed by many keen supporters of technology who presented their expectations. But they included a lot of known, highly used and not addressed reasons for limited technological advancement in the classroom or for learning, e.g. budget, admission, management and administration, teaching tools and materials, consultant, and calculation for future etc. which represented comparatively exciting argument, but did not consider the current Web and Internet tools and skills of the students by often bypassing the traditional learning process and techniques. The practice of the latest method of learning is not about technological use per-se but it is about the application of technology in a meaningful and constructive way which brings into effect the overall curriculum and assessment objectives too.

To recruit broader international spectators will definitely 
discourage many home-based, work-based, distance-based, and adults learning readers and are not talked in a favor of technologically equipped learning centers. Those under the influence of technology are then disposed to accept the recurring demands i.e., Internet, Web-Tools, videos, television, computer-based learning, and ultimate learning. Conversely, some arguments may run counter to this pattern; however, some of their concepts are bound to highlight the use of technology and as such are positively reflected when noticed. It is because computer is not a play thing but is a game changer in the milieu.

The use of modern technology-oriented methodology for learning is a very attractive topic which provides the fundamental content of today's education. It also demonstrates an interesting view on what might be missing and added when technology is introduced into the educational process. The study considers higher education institutions as to where and how the curriculum needs be brought on the track that reflect the dynamic nature and commitment of students to the learning practice. This means that a new curriculum be designed, but assessment processes must reflect individual learning assessment; collaborative activity, appropriate technological involvement, and different approaches for identifying problems. Only learning from technology-oriented devices or computer-based teaching devices should be considered that strengthen students' learning and knowledge skills.

The study is essentially more about higher education learners by utilizing technology in a meaningful way, that can have an access outside the formal educational setting and effectively apply different process or reconsidering education within the context of a $21^{\text {st }}$ century scientifically enabled world. It gives some space to learning that happens progressively outside the institutions. It is worth mentioning that no such book could avoid the consideration of educational leadership or the role of governments and a possible vision for the future in developing educational paradigms in the age of technology. Without investigating and practicing the modern schema for learning process, it is deeply felt that the concepts of learning theory, curriculum alignment or motivational theory fall short in the desired end.

\section{Related Work}

For the last few years, it has been observed that a knowledgeable society, organizations, and institutions construct their own education scheme for maintaining their capabilities. It enhances collaborative as well as individual learning capabilities which leads uninterrupted improvement but tends to be unplanned, informal and unexpected [4-5]. A knowledge based society, organizations, and institutions also develop education schema by giving facilities to their participants with widespread chances for encircling and reinforcement by breaking down hurdles of learning, communication, appropriating people to extend their skills, flexibility in their teamwork, looking at different problems and mistakes. The institutions are also in the struggle for increasing the socioeconomic set-ups and interaction for their participants that should consider as a hope of learning and are more than opportunities of responsibility, the involvement of everyone in the big picture and extra support for further learning [9].

Formal education survived for a century doesn't mean that it will continue unchanged and especially in the recent decades the growth and continuity in capital improvements of many countries have developed a trend for strengthening and stabilizing of higher education initiatives [10]. A common mantra submits that a teacher from hundred years ago will never be able to notice any change if enter today's classroom, although the globalization existence concept and technologically equipped society could contradict such a statement. Further, the claims of interference are more analyzed in the context of religious affairs that these are directly challenged the future goals of faculty and determination of education institutions [11-13].

Rather than irritating to expect the future, the environmental pressures on education like the influence of modern technology-oriented programs, potential focusing response areas and the appreciativeness change in differentiating portions will finally result oriented because of globalization concept. An extensive assessment of learning history reveals key modifications in disciplines and consistency; and basic technologies which support the learning schema. Outside environmental pressures incessantly support variation, containing those which are established in the federal legislature of USA and pushed organizations from traditional to modern and are concerned with agriculture and sciences and are directed to new registrations and the opening of new institutions for less elite students. They pushed these students for big scientific and practical expertise in the mid of $20^{\text {th }}$ century and directed them for a federal research grant through different agencies and big research institutions [14-17].

\section{Learning Strategies}

There are several ways for the promotion of education in which the modern technology and new pattern of training are reasonable and relevant. Individuals who have general aptitude for recognizing and negotiating with problems, along with meta-cognitive capabilities, need to improve, train, and to make connections with knowledgeable society. There are several but particularly few effective strategies that are used for easy learning; so if adopted, surely will have a positive impact on society. These are described under the following headings:

\subsection{Curriculum Development}

The curriculum is the schema for schooling and learning in institutions. It plans the matters taught and the information, services and agenda essential for each course. It also bifurcate sub categories and domains for each course, thus bordering objectives that learners should be stimulated to 
realize [21].

Furthermore, the curriculum also regulates the determination technique that is used to enhance learner's progress. Tutors, institutions, and organizations have the liberty to select the best way to communicate the curriculum to students, and how to make their own lesson plans, scheme of studies and book learning methods according to their learners, individual necessities.

At the start of every academic session, such plan and scheme have been prepared for each class and are followed throughout the year. Appendix D shows a sample of scheme of studies and lesson plan.

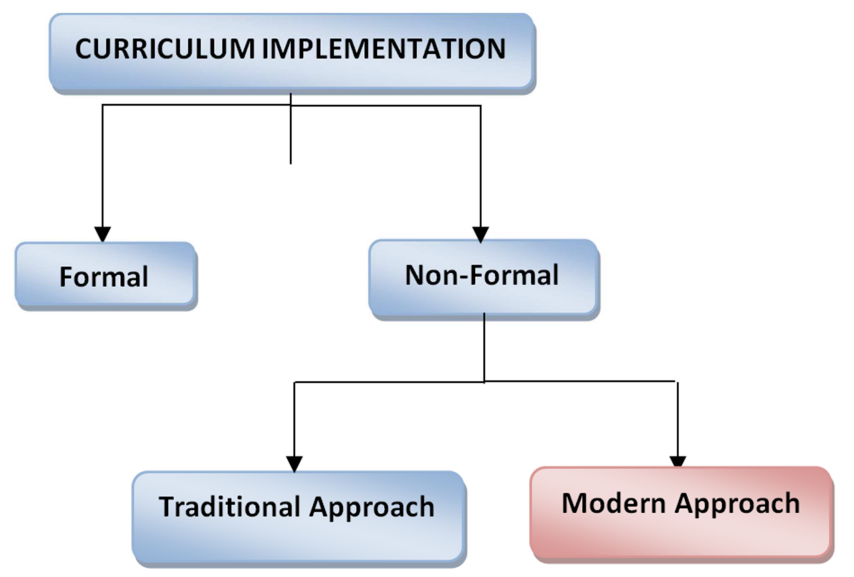

Figure 1. Lesson Plan and Scheme of Studies Preparation.

\subsection{Use of Technology}

Modern technology can be exploited and used for education in the following perspectives:

1. Technology is ideally much suitable for personal planning, obligating and arranging different procedures for learning and is suitable for tutors in developing the learning schema for learners.

2. Guiding creative and comprehensive assessments of pupils is undoubtedly a dream for teachers, since learners are not in mode of taking a specified assessment at the same time. Once again, technology can be of great assistance. Technology offers tools that help teachers to improve assessments for finding good and bad among students.

3. Technology provides pedagogical tools like tutorials, drill \& practice, simulations, communication and research tools, and learning materials when performing a task. It also provides tools for observing, controlling, managing and supporting learner's skills and knowledge, facilitates and helps teachers and developers for launching new tasks and preparing instructional tools for future learners [15].

4. Technology is used to select long-term goals for all stakeholders. It also helps to identify the full range of achievement opportunities among the students.

5. Technology is used for specifying teacher-parents' and any other stakeholder's role that can play in supervising the students in learning for a specified task. It also develops accountability for identifying tasks, aims and objectives, teamwork, students' characters and places a deadline for accomplishing a task [21].

6. It is worth mentioning that technology plays a key role in the post-industrial standard of education. It also enables a considerable progress in an individual for learning for a less cost per learner per year than in the current commercialized era of education, where a student needs to buy different books; makes a photocopy of different teaching materials and go for searching libraries [24]. In this regard G.Muppudathi in 2014 skitch different stages for a tutor who use technology for learning, as shown below in figure 2 .

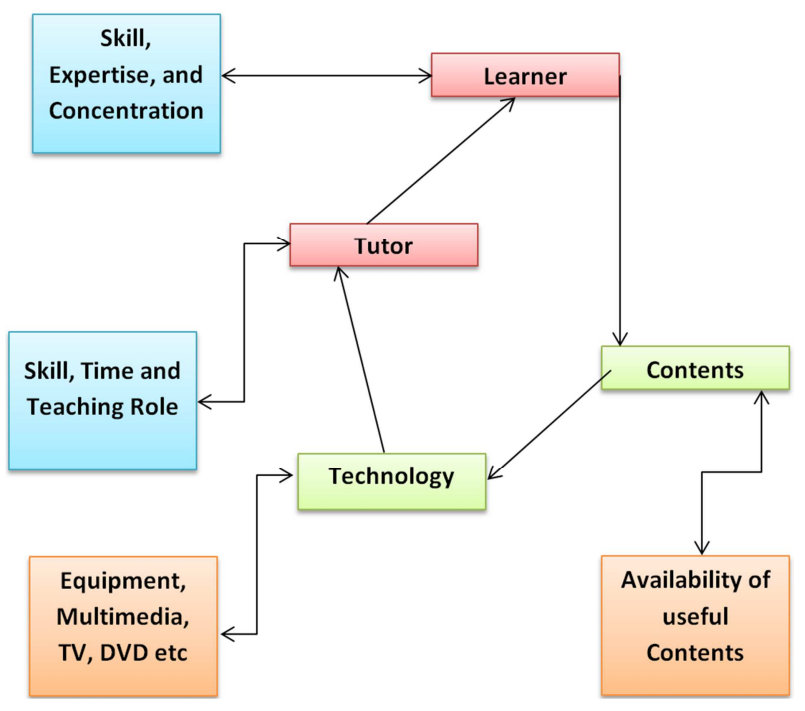

Figure 2. Teaching with Technology-A diagrammatic overview.

It is mandatory for a tutor to have skills, time, and being a teacher must be interested in learning with full zeal and zest, specifically tempered with technology. The useful course contents shall also efficiently and effectively describe the object, place or event. Similarly, modern technological equipments like Multimedia projector, TV, Tablets, smartphone and application programs are supposed to be functional.

In this regard, a study was conducted to investigate the use of technology by both teachers and students for learning for which $41 \mathrm{BS}$ students of different disciplines and 7 teachers were investigated. An online survey was sent to the students regarding their use of technology and the devices they use. In the questionnaire, they were asked for using what type of study aid materials especially electronic do they use. The response was: laptops $(50 \%)$, smart-phones $(42 \%)$, tablets $(7 \%)$ and desktop computers $(0.5 \%)$. From this survey, it has been observed that technology usage might produce rather more significant increase in academic achievement than would non-usage.

Granted that the respondents were not fully equipped and yet their results were not very bad, it revealed that the students relied on meager learning in line with a set pattern of famous Bloom taxonomy. Electronic and technological assistance in this regard is of extreme help and is as systematic as the taxonomy itself. This lack is somewhat compensated by the procedural stages of the taxonomy $[3,5]$. 
The educational goals achieved in a learning environment, Bloom's taxonomy (BT) plays an important role. Benjamin Bloom created a categorization of learning objectives to evaluate learning outcomes. Several studies have been conducted for automatic labeling of questions using Bloom's taxonomy (BT). These questions are used for designing an effective test in order to evaluate the skills of a participant using the taxonomy. Those studies yielded systems for labeling questions using Artificial Neural Networks (ANN), a Rule-Based classifier and a bank of words using weights for each category (Armour-[15]. However, it is important to notice that those studies addressed the automatic labeling of questions, which is not equivalent to a text containing expressions and thoughts from a person. Additionally, a study by implemented a system for automatic labeling of discussion forums, but a deeper analysis of the results was not performed. As far as we know, there is not a relevant study about the automatic labeling of discussion forums [3]. The Taxonomy is shown below in the figure

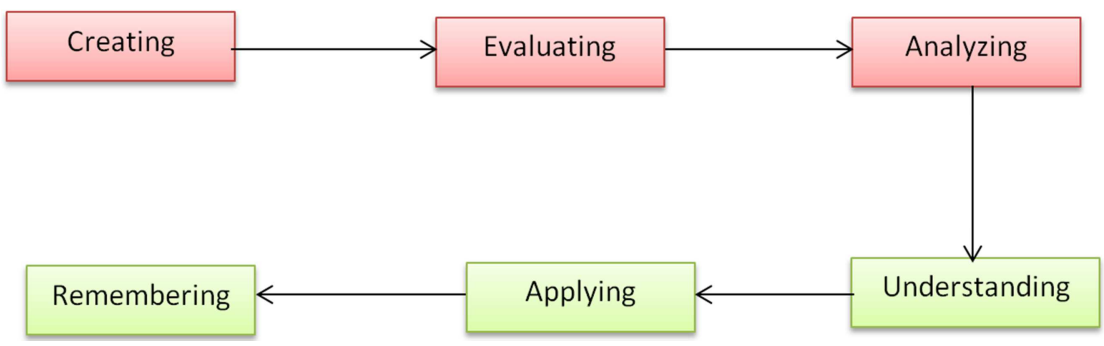

Figure 3. Bloom Taxonomy.

\subsection{Use of Internet}

Internet is available everywhere and is a widespread phenomenon: constructed through forecast, networks websites, and online journals and is used by millions of people around the world. The current conversion of communication technology into digitizing age maximizes the scope of communication broadcasting to every sphere of social life personalized in an ever-changing configuration. What illustrates the current method of communication, based on the computerized, networked incorporation of numerous communication representations, is its completeness and extensiveness of all social terminologies [25].

For example, through web, researchers see images of black holes in space, historic photographs, artwork, or look at satellite imaging or MRI scans or some websites. Similarly, a topic or a lesson can be manipulated or rotated, so that students can see them from different angles and thereby understand difficult concepts in an easy manner. The Internet is particularly well-suited for communication and collaboration, research, real-time data collection and web publishing [10].

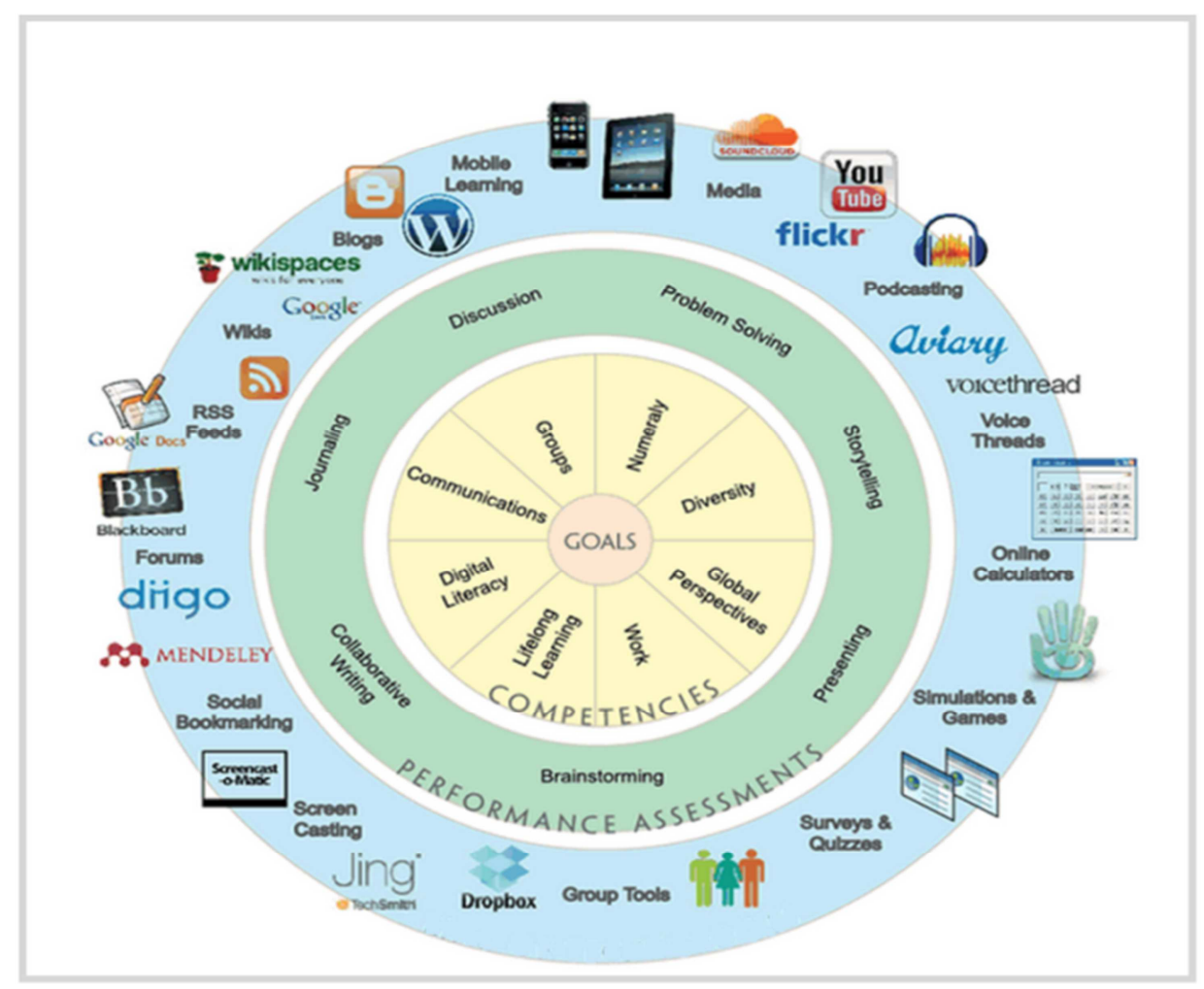

Figure 4. Different facilities available on Internet for Learning. 
Different conventional tests were designed for students wherein they showed considerably low performance: they yielded $49 \%$ result as shown in the appendix A. These tests were followed by the non-conventional, technology affected tests that is through Internet and graphic mediums and the result was dramatic. This time the result was $66 \%$ and $87.7 \%$ respectively as shown in appendix $\mathrm{B}$ and $\mathrm{C}$. This marked improvement could be attributed to a more sophisticated but less complex use of information technology.

\subsection{Dialogic Method}

Dialogic method of learning is used by a growing number of scholars, practitioners and policy-makers to describe learning processes, in which teacher and pupils critically interrogate the topic of study, express and listen to multiple voices and points of view, and create respectful and equitable classroom relations [26]. In this method the tutors educated without facing hurdles like the division of this world into rigid and self-referencing sections. It is generally understood that those tutors who depend more on language show slight flexibility when it comes into consideration of the contrasting assessments and thoughts of the learners. In a broader sense, teachers can either attitudinize the problems aimed at a predefined answer or taking a lecture from lessons, have a major implication from socio-cultural perspective. Simply, this method uses talking technique that is effective for carrying out teaching/learning process [11]. It comprises a verbal continuity among tutors and learners, not just the lecture of a tutor. The tutors in this method can elicit student's daily knowledge perceptions, involve them for developing different ideas and help them to swamped mistakes and confusions; learners are habituated to delivered views in the classroom via dialogue to spread and in diverse ways that can also extend the boundaries of their own generous. Together, they also are practice a new method of using language as a tool for formulating knowledge.

By prepossessing learners in dialogue, tutors can:

a) Illuminate ideas; simplify the point and determination of all activities and present general model in scientific ways of using language.

b) Help learners understand something new, scientific ways of describing the phenomenon, practice learners and finally, go and teach others; as shown in the chart above.

Without defining population, it is impossible to draw result from the questionnaire/survey or direct approach. The participants (BS Students) were interviewed for the aforesaid technique (direct approach) during their class's hours and they states that the dialogic method of learning appears to be a balance coverage for them and a wide spectrum of knowledge were gained in this approach instead of conventional learning process. The survey has been made to recruited the BS students, but the results be generalized for all learners.

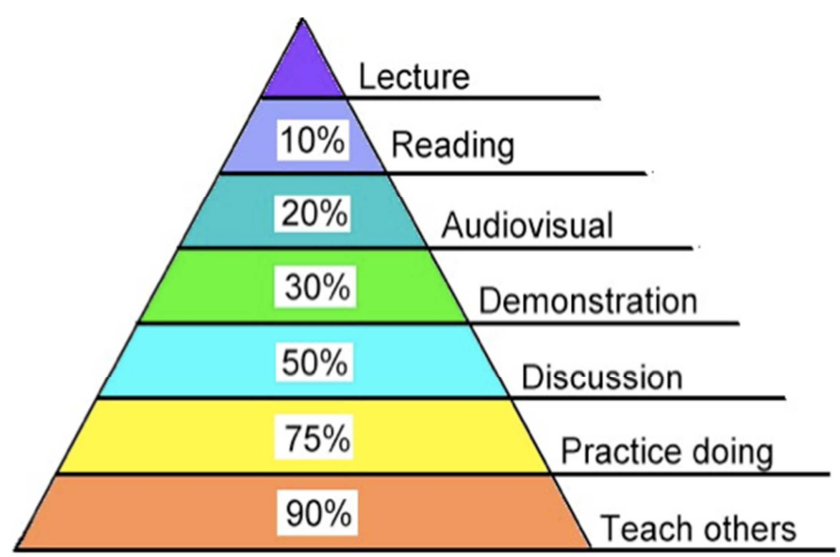

Figure 5. Dialogic Method of Learning.

\subsection{Recursive Method}

It is a method aimed at understanding systemic dynamics and the circular process of reality. A type of knowledgebased learning and planning system called status selection learning and planning system, that has the capacity of solving a problem, depends specifically on the status selection set of rules [5].

This knowledge-based planning system uses inductive learning methodology which is very useful for learning. It is divided into six phases; arrangement of a training session, setting and learning everyone inductively and enforce them to strictly follow scheme of studies/lesson plan as shown in the figure:

Table 1. Recursion Method used in Mathematics.

\begin{tabular}{llll}
\hline Steps & Procedure & Output \\
\hline 01 & 10 & Write_Vertical(52406), $\mathrm{n}=52406, \mathrm{n} / 10=5240, \mathrm{n}$ (modulus) 10 or $+\mathrm{n} \% 10$ & 5 \\
02 & 09 & Write_Vertical(5240), $\mathrm{n}=5240, \mathrm{n} / 10=524, \mathrm{n}$ (modulus) 10 or $+\mathrm{n} \% 10$ & 2 \\
03 & 08 & Write_Vertical(524), $\mathrm{n}=524, \mathrm{n} / 10=52, \mathrm{n}$ (modulus) 10 or $+\mathrm{n} \% 10$ & 4 \\
04 & 07 & Write_Vertical(52), $\mathrm{n}=52, \mathrm{n} / 10=5, \mathrm{n}$ (modulus) 10 or $+\mathrm{n} \% 10$ & 0 \\
05 & & Write_Vertical(5), $\mathrm{n}=5, \mathrm{n} / 10=5, \mathrm{n}$ (modulus) 10 or $+\mathrm{n} \% 10$ & 6 \\
06 & & Write_Vertical(5), $\mathrm{n}=5, \mathrm{n} / 10=5, \mathrm{n}$ (modulus) 10 or $+\mathrm{n} \% 10$ & Stop Recursion \\
\hline
\end{tabular}

It occurs when an object is defined by itself or by its type. It is used in a range of disciplines varying from linguistics to logic, as explained by solving the example below:
Recursive method of learning is most commonly used in computer science and mathematics, where each and every problem is explained, and functions within its own pre- 
defined definition or formula. This is actually defined because of an infinite number of requests coming from a user towards server referred to as function values, often performed in a manner that no repetition or infinite chain of references can occur.

Recursive method of learning is used for Inquiry process, an active learning that is driven by questioning and critical thinking. The understandings that students develop through inquiry are deeper and longer lasting than any pre-packaged knowledge delivered by teachers to students. Inquiry-based learning follows a process that progresses through phases, but is recursive and reflective throughout. The six phases (Library of Congress, 2008) and their thought processes are detailed in the following diagram.

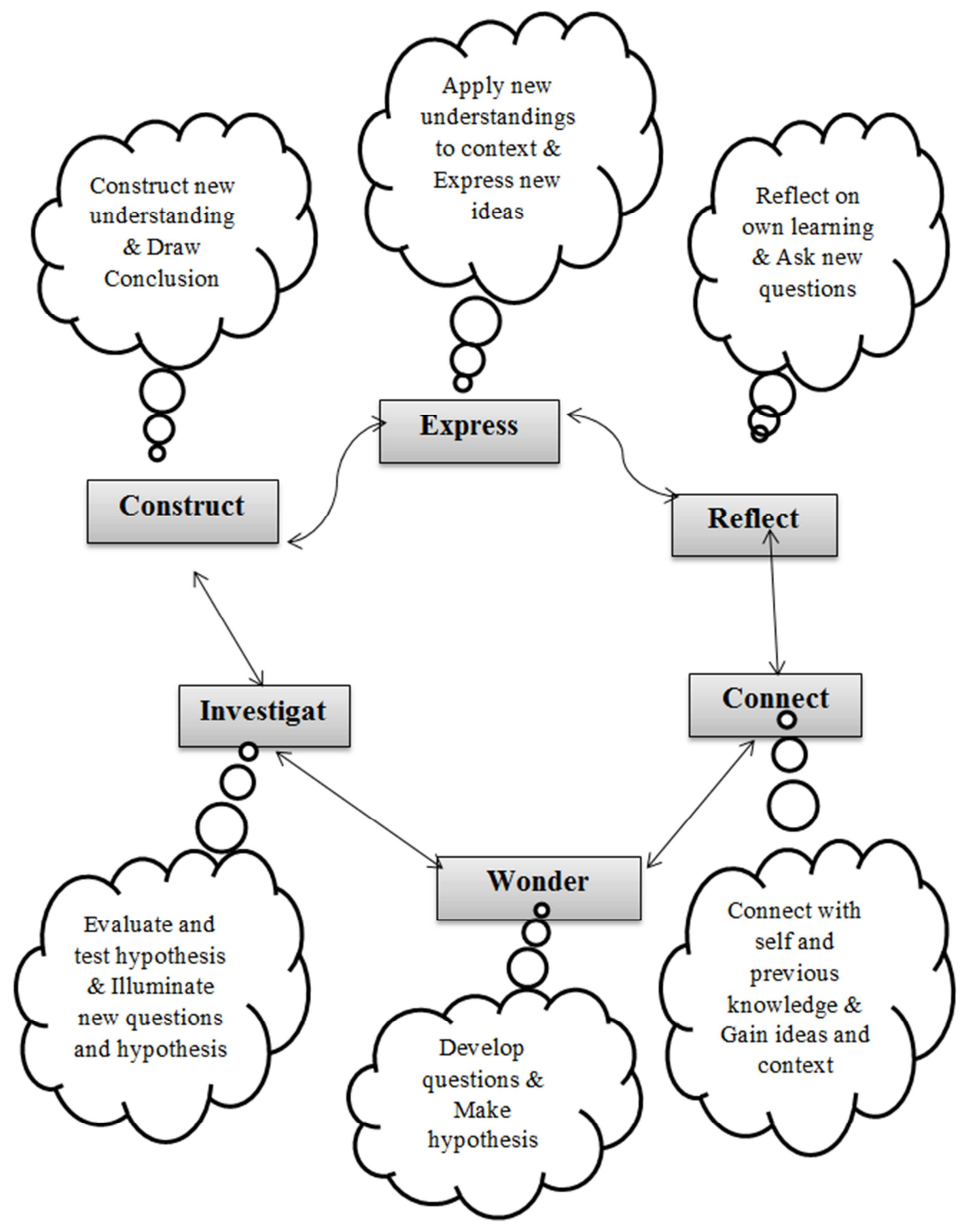

Figure 6. A diagrammatic representation of Recursive method of learning.

This method has been recommended by different educationists for those tutors who teach Physics, Computer Science, Mathematics and any natural science subject. They may benefit from the recursive methodology shown in the diagram. It focuses on an idea and prepares a well-organized plan for learners to pick it up for further research; it collects and evaluates the difficult idea from all aspects and share knowledge with experts. Before completion of the first cycle, they have to go for the second and follow each step till finding its goal and vice versa. 


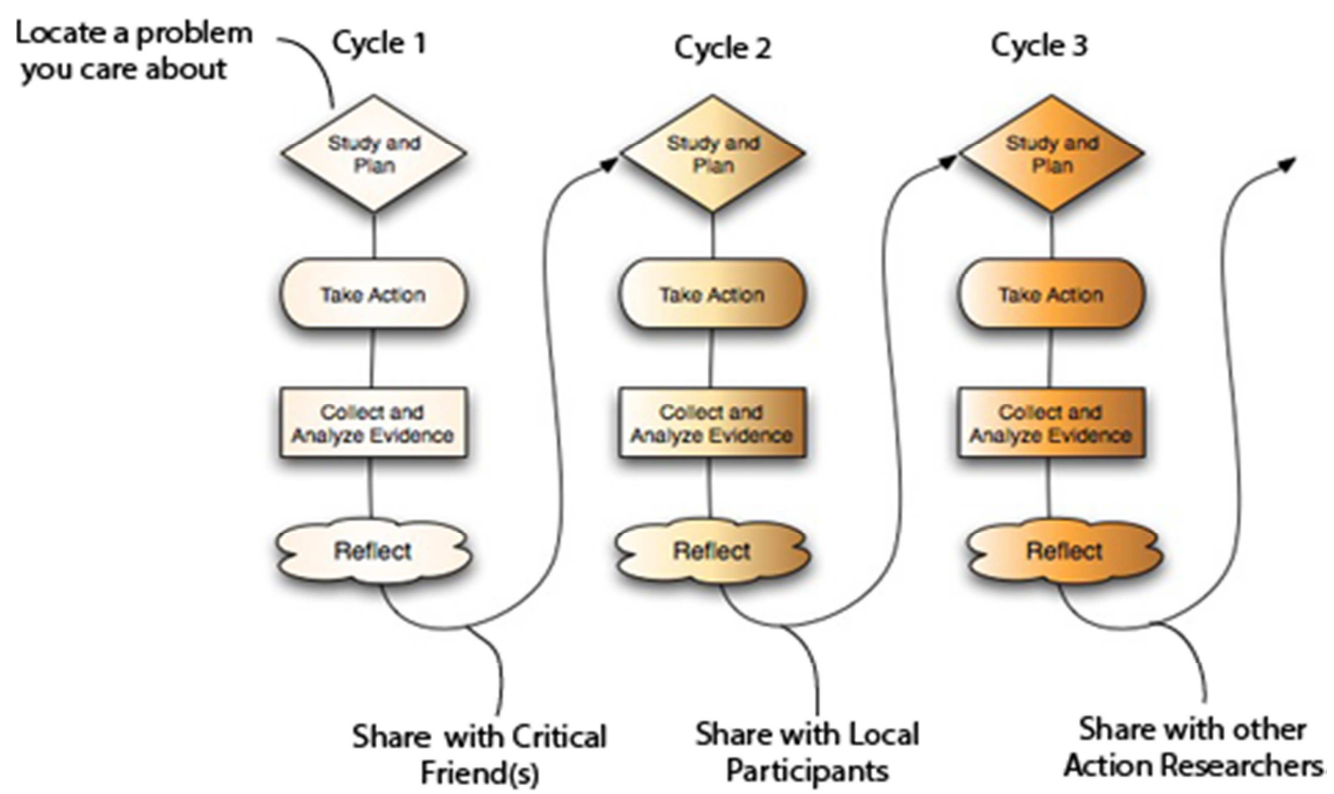

\subsection{Holographic Methods}

A method through which can enrich parts of our knowledge with the whole or the whole with parts. The holographic approach is itself linked to the recursive approach, which in turn is linked to the dialogic approach [5$6]$.

The recent advancements in technology have proven that learning is not a meager response to delivery but is an energetic, productive, intellectual and social process through which the student deliberately accomplishes cognitive, somatic, and social assets to generate new knowledge. Whereas still in its actual stage of learning, 3D hologram or holographic technology can be the means that change the manner of develop and delivering knowledge.
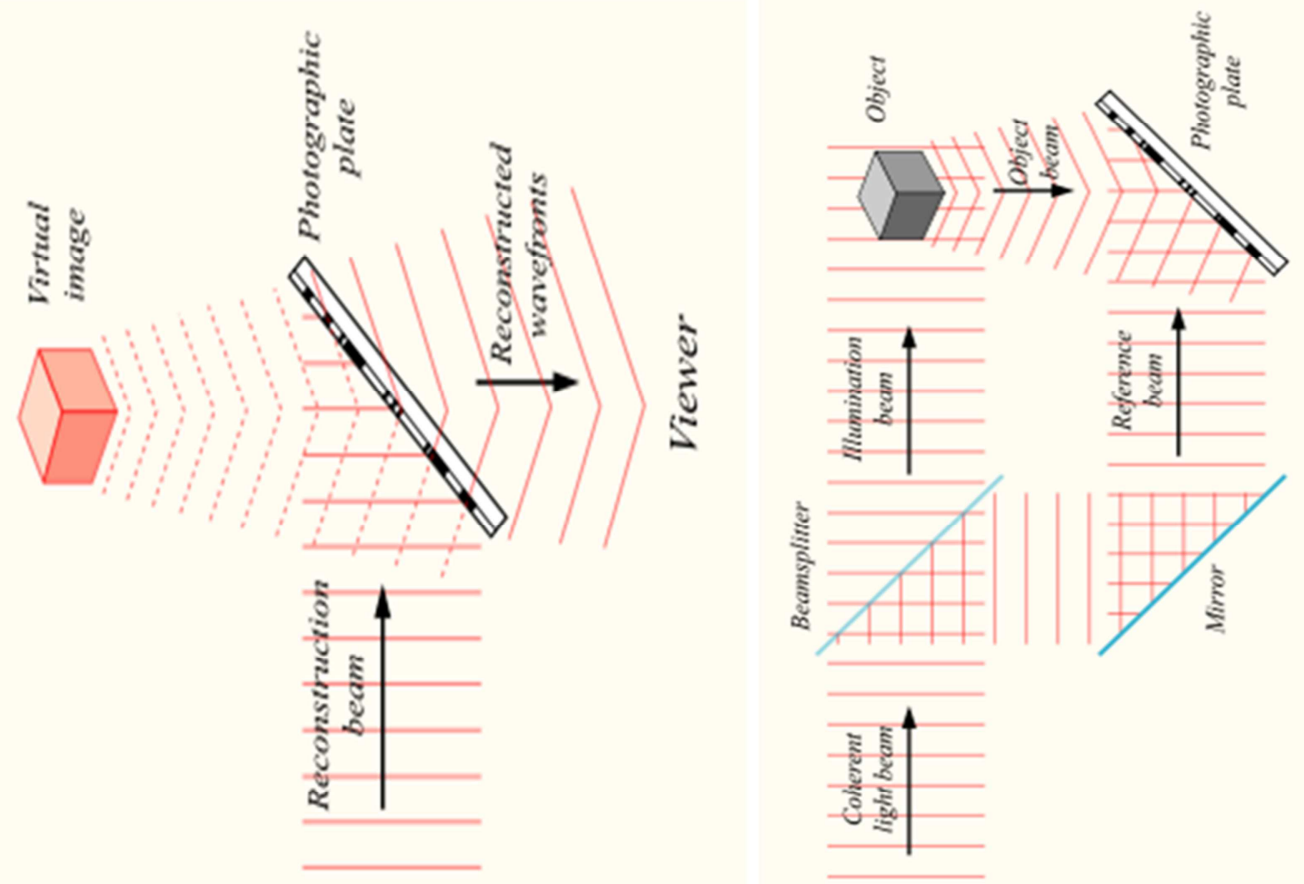

Figure 8. Recoding and Reconstructing a Hologram.

Holograms are created and used by different and most popular institutions of the world for teaching and training. The learners of these institutions regularly participate in the labs for learning using this approach. They are working to learn the wave/dual nature of light in a physics lab, the skeletal system of a human in the biology lab and so on, as shown in the figure below: 


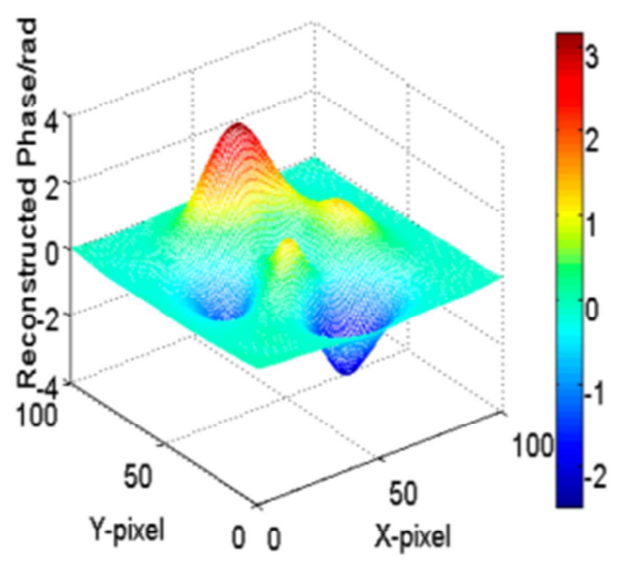

(a)

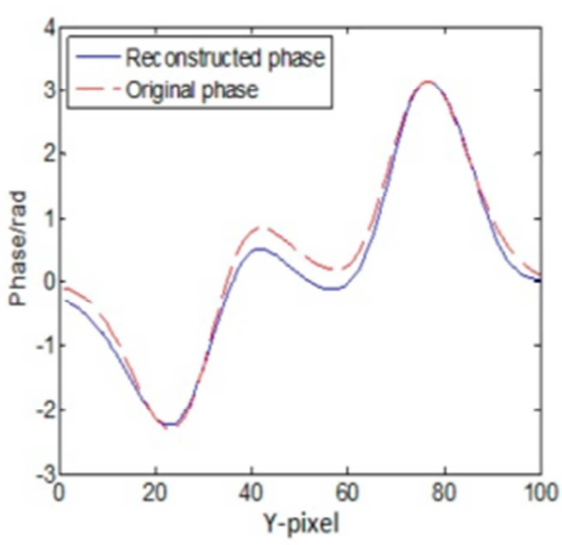

(b)

Figure 9. Holographic Method of Learning for Waves.

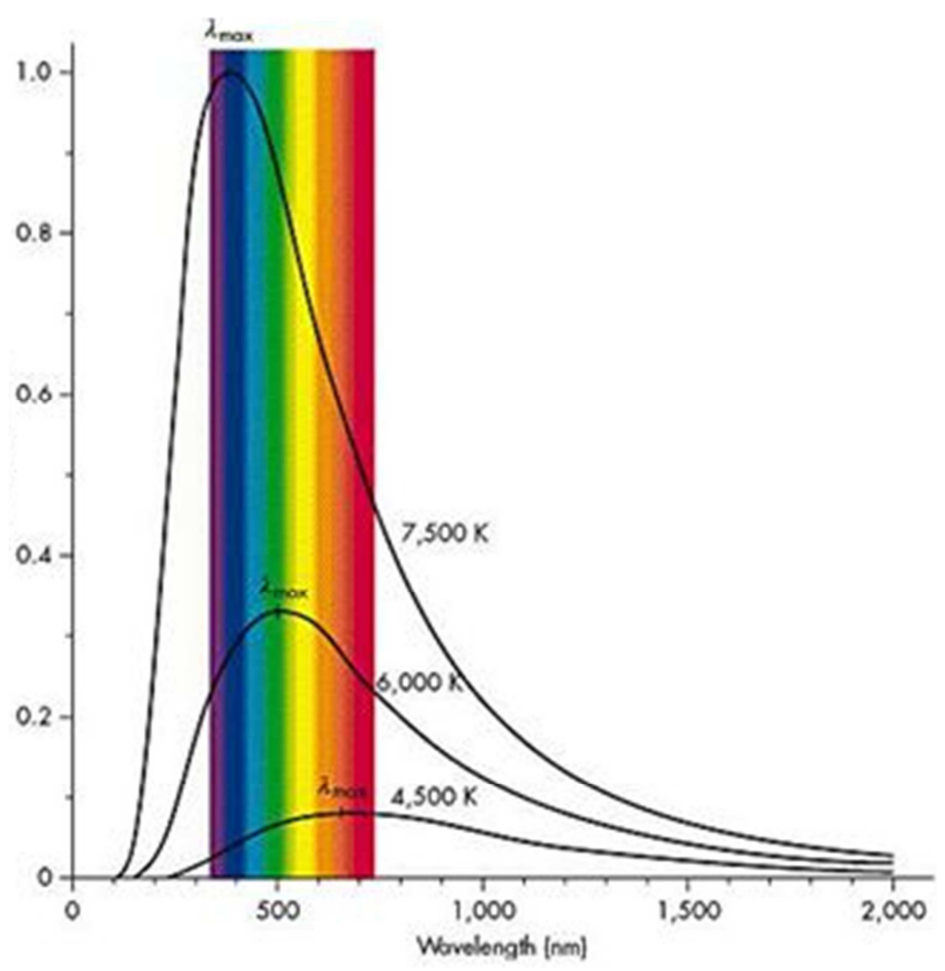

Figure 10. Holographic Method of Learning for Dual Nature of Light.

\section{Conclusion}

The current trend towards learning and knowledge as a global public phenomenon could expand the access and opening up of education exponentially. As human is prosthetic by nature so it seems odd to approach all the possible uses of learning through the use of technology. The capabilities and contingencies that information technology can pitch in education are tremendous and impressive. Before these can turn up, comprehensive, well-organized and wellaccomplished initiatives must be circulated for education. However, by introducing IT essentials comprehensively and systematically for learning pattern and dynamic proficiency in education instantaneously; tutors also have a key and energetic role to justify and making the perception of an ITskilled and vigorous future generation as a reality. It cannot adequately restate that teachers are the main actors in the accomplishment of these new initiatives in education. Even though the transformation is neither easy nor smooth, teachers and all stakeholders have a lot of responsibilities in regulating, readjusting and relearning to do it for the future generation. The different educational stakeholders can contribute, boost and strengthen each other in several ways, so as to make the initiatives more enjoyable and less challenging. Once the initiatives become less problematic, the opportunities and potentials that proposed can gradually but confidently become dashes of realism. 


\section{Appendix}

Appendix $-A$

EVOLUTION QUESTIONNAIRE/TEST

Q/No. 01: Fill in the Blanks

i. Primary Memory is ONLINE to processor.

ii. SRAM FASTER than DRAM, need not to be REFRESHED continuously.

iii. ENIAC stands for ELECTRONIC NUMERICAL INTEGRATOR AND COMPUTER.

iv. The visible/non-touchable part of the computer is called SOFTWARE.

v. The memory sandwich RAM and CPU called CACHE MEMORY.

Q/No. 02: Encircle the correct answer

i. Which one of the following is not a high level language?
a) C Language
b) $\mathrm{C}++$ Language
c) Assembly Language
d) Java

ii. Secondary memory is also called, which one of the following?
a) Online Memory
b) Temporary Memory
c) Volatile Memory
d) Auxiliary Memory

iii. SRAM is made from, which one of the following?
a) Transistors
b) Flip-flop Circuits
c) Capacitors
d) IC's

iv. Which one of the following is an example of application software?
a) Window
b) Linux
c) Dreamweaver
d) Android

v. Fetching, execution and controlling is, which one of the following?
a) Processing Operation
b) Storage Operation
c) Input Operation
d) Non

Q/No. 03: Mark true for correct answer otherwise false, for the following, overwriting is prohibited? (5)
i. Software is nothing without hardware.
(True/False)
ii. Thermometer is an example of digital Computer.
(True/False)
iii. Abacus is said to be the first computer.
(True/False) _
iv. DVD stands for digital versatile disk.
(True/False)
v. Android is an Application Software.
(True/False) _ F

Q/No. 04: Any given statement in Column I can have correct matching with one statement given in Column II, Rearrange the following correctly? (5)

\begin{tabular}{|c|c|c|c|}
\hline Column I & Column II & Column I & Column II \\
\hline Unit of Memory & ENIAC & Unit of Memory & Bit \\
\hline Primary Memory & Window & Operating System & Window \\
\hline First Digital Computer & Bit & First Digital Computer & ENIAC \\
\hline $1024 \mathrm{~GB}$ & $\mathrm{~TB}$ & $1024 \mathrm{~GB}$ & $\mathrm{~TB}$ \\
\hline Operating System & ROM & Primary Memory & ROM \\
\hline
\end{tabular}

Q/No. 05: Define the following terms? To the point answer shall be considered. (10)
1. Cache
2. Software
3. EEPROM
4. Flash Memory
5. Memory Hierarchy
6. Analog Computer
7. General Purpose Application Software
8. Byte
9. DRAM 


\section{Computer}

Terminilogies are briefly discussesed under the following heading for social sicences and humanities group learners:

1) Cache: To compensate the speed difference between RAN and CPU, a memory is inserted called Cache.

2) Software: A program set of instructions that run hardware, the visible part, and non-touchable/nonphysical part of the computer is called software.

3) EEPROM: Stands for Electrically Erasable Programmable Read Only Memory. It is a chip, fixed on the motherboard of a computer capable for step-by-step boosting of computer. Also contains information about a company/manufacturer; and the data stored in this type of ROM can be erased electrically using a specialized machine.

4) Flash Memory: A type of memory that holds data in the nonexistence of a power supply.

5) Memory Hierarchy: On the basis of size, the memory hierarchy are as under:-

6) Bit - (Nibble (4Bit)) - (Byte(8Bit)) - (Word (16Bit)) - (Double-Word(32Bit)) - (Quad-Word((64Bit)). Similarly, 1024 Byte $=1$ Kilo Byte $(\mathrm{KB}) 1024 \mathrm{~KB}=1$ Mega Byte $(\mathrm{MB}), 1024 \mathrm{MB}=1$ Giga Byte $(\mathrm{GB}) \& 1024$ GB = 1 Tera Byte $(\mathrm{TB})$. On the basis of speed/performance, the memory hierarchies are as: Register - Cache - RAM+ROM - HardDisk/CD/DVD/VCD - Magnetic Tape etc.

7) Analog Computer: An analog computer or analogue computer is a form of computer that uses the continuously changeable aspects of physical phenomena such as electrical, mechanical, or hydraulic quantities to model the problem being solved. Example Thermometer, Librascope, aircraft weight and balance etc.

8) General Purpose Application Software: It is a type of application that can be used for a variety of tasks. It is not limited to one particular function. For example a word processor could be classed as general purpose software as it would allow a user to write a novel, create a restaurant menu or even make a poster. Example MS - Office, Dreamweaver, word processors, spreadsheets, databases, desktop publishing packages, graphics packages etc.

9) Byte: A byte is considered to be a unit of memory size that is equal to 8 Bit.

10) DRAM: Dynamic random access memory (DRAM) is a type of memory that is typically used for data or program code that a computer processor needs to function. DRAM is a common type of random access memory (RAM) used in personal computers (PCs), workstations and servers. It is slower than SRAM, it made from capacitors and need continuous refreshing.

11) Computer: Computer is an electronic device that is designed to work with Information. The term computer is derived from the Latin term 'computer', this means to calculate or programmable machine. Computer cannot do anything without a Program. OR It is a machine in which we give Input, it can process the input and give output information. OR A machine that can operate on digital signals is called computer.

\section{Appendix - B}

1. This is section A. You have to return this sheet to the examiner within 20 minutes.

2. Copying, cutting, talking is strictly prohibited, and may lead to the cancellation of your paper

SECTION-A

Time allowed: 20 minutes

Marks: 12

Q1: a) Fill in the blanks:

i. Part of CPU capable for controlling, managing and supervising the overall activities is

ii. To translate any High-Level-Language into machine Language line-by-line is

iii. The Memory between and is called cache.

b) Choose the correct answer:

(03)

$i$. Which one of the following is an example of simplex modes of data communication?
a. Computer
b. Walkie-Talkie
c. TV/Radio
d. None of these

ii. The network formation using $n(n-1) / 2$ is termed as
a. Ring Topology
b. Mesh Topology
c. Star Topology
d. Bus Topology
iii. The first digital Computer was
a. Abacus
b. Micro Computer
c. Mini Computer
d. ENIAC

c) Identify as true or false.

i. The network within $100 \mathrm{~m}$ distance is called Local Area Network

(True/False)

ii. To convert the High-Level-Language into Machine Language is a whole called Assembler (True/False) 
d) Define the following. (04)

1. Synchronous and Asynchronous Modes of Communication

2. Collaborative Computing and Social Networking

\section{SECTION-B}

Time Allowed: 40 mins

Maximum Marks: 08

NOTE: Return both answer sheet and question paper to the superintendent within due time. Answer the following questions. Your writing must be precise, concise and legible.

Q2: Define and Explain Computer Memory and its types in detail.

Q3: State and explain Components of a computer system in detail.

\section{Appendix - C}

\section{Note Please}

1. This is section A. You have to return this sheet to the examiner within 20 minutes.

2. Copying, cutting, talking is strictly prohibited, and may lead to the cancellation of your paper

SECTION-A

Time allowed: 20 minutes

Marks: 12

Q1: a) Fill in the blanks:

i. To minimize the number of netw ork lines using general intelligence is called

ii. MAN stands for

iii. To translate a source code into object code as whole is the work of

b) Choose the correct answer: (03)

i. Which one of the following is an example of simplex modes of data communication?
a. Computer
b. Walkie-Talkie
c. TV/Radio
d. None of these

ii. The network formation using $n(n-1) / 2$ is termed as
a. Ring Topology
b. Mesh Topology
c. Star Topology
d. Bus Topology

iii. The first digital Computer was
a. Abacus
b. Micro Computer
c. Mini Computer
d. ENIAC

c) Identify as true or false.

i. Compact Disk (CD) is a type of flash memory

(True/False)

ii. To convert the High-Level-Language into Machine Language is a whole called Assembler (True/False)

d) Define the following.

1. Bus

2. Collaborative Computing and Social Networking

SECTION-B

Time Allowed: 40 mins

Maximum Marks: 08

NOTE: Return both answer sheet and question paper to the superintendent within due time. Answer the following questions. Your writing must be precise, concise and legible.

Q2: Define and Explain Network Topology along with block-diagrams in detail. (04)

Q3: State and explain Classification of Computer and Types of Computer in detail. (04) 


\section{Appendix-D}

A Lesson Plan/Scheme of Studies prepared at the start of the session for achieveing goals and establishing an efficient and effective learning environment in the class room.

\begin{tabular}{|c|c|c|c|}
\hline $\begin{array}{l}\text { Chapter } \\
\text { Number }\end{array}$ & $\begin{array}{l}\text { Topic/subtopic Name with complete description tha } \\
\text { mentioned time frame }\end{array}$ & at should be covered in the & $\begin{array}{l}\text { Estimated Time } \\
\text { Frame for covering } \\
\text { the mentioned topics }\end{array}$ \\
\hline 02 & 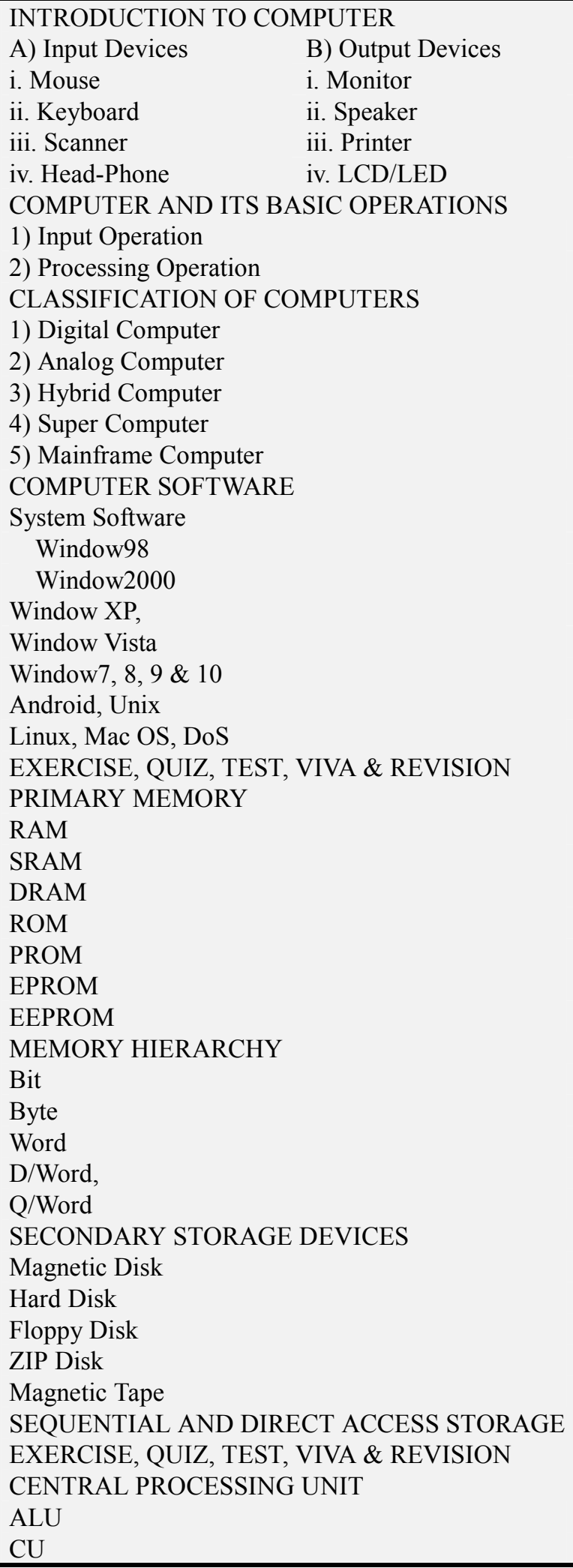 & $\begin{array}{l}\text { C) Processing Devices } \\
\text { i. Primary Memory } \\
\text { ii. Secondary Memory } \\
\text { iii. CPU } \\
\text { iv. BUS / Port } \\
\text { 3) Output Operation } \\
\text { 4) Storage Operation } \\
\text { 6) Mini Computer } \\
\text { 7) Mainframe Computer } \\
\text { 8) Personal Computer } \\
\text { 9) Laptop/Tablet/Desktop } \\
\text { 10) Cell - Phone } \\
\text { Application Software } \\
\text { General Purpose } \\
\text { Special Purpose } \\
\text { Firmware } \\
\text { Freeware } \\
\text { Shareware } \\
\text { Virus. } \\
\text { AutoCAD } \\
\\
\text { Cache } \\
\text { Register } \\
\text { AC } \\
\text { PC } \\
\text { MAR } \\
\text { MBR } \\
\text { Flag } \\
\text { KB } \\
\text { MB } \\
\text { GB } \\
\text { TB } \\
\text { Flash Memory } \\
\text { CD } \\
\text { DVD } \\
\text { VCD } \\
\text { BRD } \\
\end{array}$ & $\begin{array}{l}16 / 10 / 2017 \\
17 / 10 / 2017 \\
18 / 10 / 2017 \\
23 / 10 / 2017 \\
24 / 10 / 2017 \\
25 / 10 / 2017 \\
06 / 11 / 2017 \\
07 / 11 / 2017\end{array}$ \\
\hline
\end{tabular}




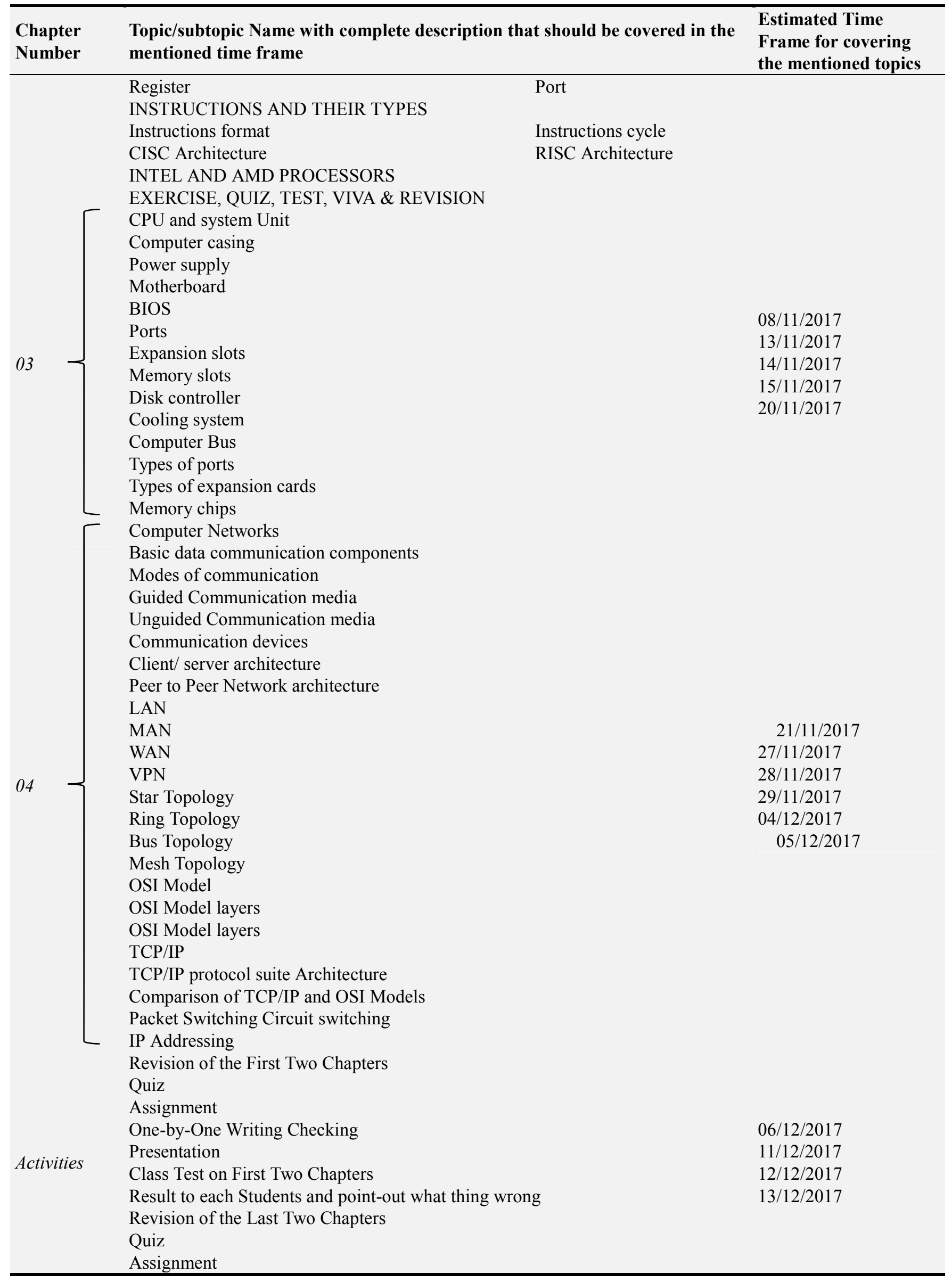




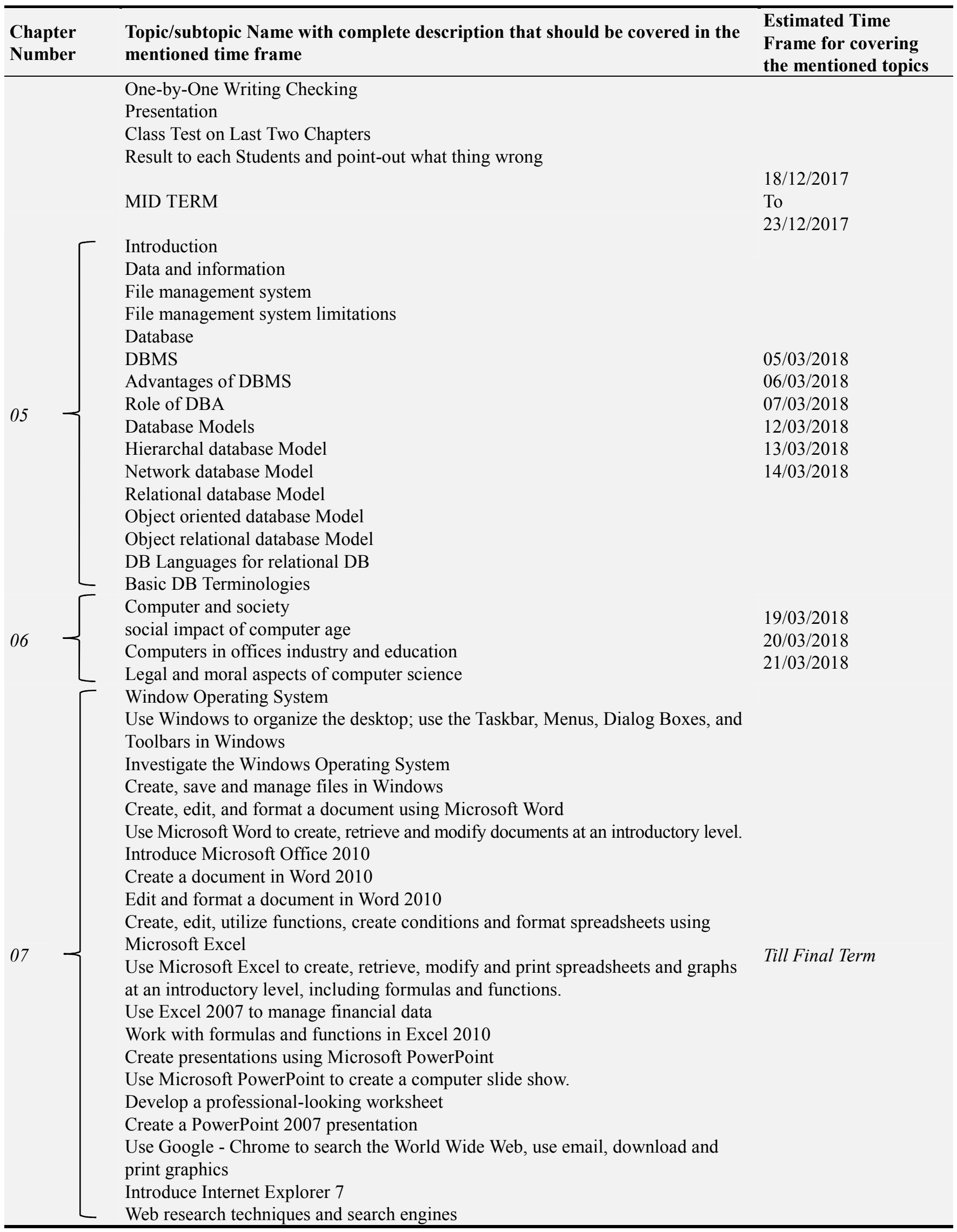




\section{References}

[1] Altbach, P. G., Berdahl, R. O., \& Gumport, P. J. (Eds.). (2011). American higher education in the twenty-first century: Social, political, and economic challenges. Baltimore, MD: Johns Hopkins University Press.

[2] Altbach, P. G., Reisberg, L., \& Rumbley, L. (2010). Trends in global higher education: Tracking an academic revolution. Paris, FR: UNESCO \& Sense Publishers.

[3] Anderson, L. W., Krathwohl, D. R., Airasian, P., Cruikshank, K., Mayer, R., Pintrich, P.,... \& Wittrock, M. (2001). A taxonomy for learning, teaching and assessing: A revision of Bloom's taxonomy. New York. Longman Publishing. Artz, AF, \& Armour-Thomas, E.(1992). Development of a cognitivemetacognitive framework for protocol analysis of mathematical problem solving in small groups. Cognition and Instruction, 9(2), 137-175.

[4] Anderson, L. W., Krathwohl, D. R., Airasian, P., Cruikshank, K., Mayer, R., Pintrich, P., \& Wittrock, M. (2001). A taxonomy for learning, teaching and assessing: A revision of Bloom's taxonomy. New York. Longman Publishing. Artz, AF, \& Armour-Thomas, E.(1992). Development of a cognitivemetacognitive framework for protocol analysis of mathematical problem solving in small groups. Cognition and Instruction, 9(2), 137-175.

[5] Barber, B. R. (1995). Jihad vs McWorld. New York: Times Books.

[6] Barber, M. (2001). High expectations and standards for all, no matter what: Creating a world-class education service in England. In M. Fielding (Ed.), Taking Education Really Seriously: Four years hard labor. New York: Routledge/Falmer Press.

[7] Barber, M., Donnelly, K., Rizvi, S., \& Summers, L. (2013). An avalanche is coming: Higher education and the revolution ahead. London, UK: Institute for Public Policy Research. Retrieved from http:// www.ippr.org/publication/55/10432/anavalanche- is-cominghigher-education and- the-revolution-ahead.

[8] Bauman, Z. (1998). Globalization: The human consequences. Oxford: Basil Blackwells.

[9] Brown, P., \& Lauder, H. (2001). Capitalism and Social Progress: The future of society in a global economy. Basingstoke, Hampshire; New York: Palgrave.

[10] Carnoy, M. \& Castells, M., 'Sustainable Flexibility: A prospective study on work, family, and society in the information age', OECD Working Paper, V (29), Paris: OECD, p. 33.

[11] Castells, M. (1998). End of Millennium. Oxford: Blackwell.

[12] Cochran-Smith, M., \& Lytle, S. (1999). 'Teacher Learning Communities'. Review of Research in Education, 24, 24-32.

[13] Coleman, J. (1988). 'Social Capital in the Creation of Human Capital'. American Journal of Sociology, 94 (Supplement), 595-620.

[14] Datnow, A., Hubbard, L., \& Mehan, H. (2002). Extending Educational Reform: From one school to many. London: Falmer/Routledge Press.

[15] Duffy, T. M., \& Raymer, P. L. (2010). A practical guide and a constructivist rationale for inquiry-based learning.

Educational Technology, 50(4), 3-15.

[16] Earl, L., \& Katz, S. (in press). 'Leading schools in a datarich world'. In K. Leithwood, P. Hallinger, K. S. Louis, G. Furman-Brown, P. Gronn, B. Mulford, \& K. Riley (Eds.), Second International Handbook of Educational Leadership and Administration. Dordrecht: Kluwer Academic Publishers.

[17] Jeffrey, B., \& Woods, P. (1996). 'Feeling Deprofessionalized: The Social Construction of Emotions During an OFSTED Inspection'. Cambridge Journal of Education, 126(3), 235-343.

[18] Jan, Saeed Ullah (2017). An Improved Lightweight Privacy Preserving Authentication Scheme for SIP-Based-VoIP Using Smart Card. Anchor Academic Publishing

[19] Jan, S. U. (2017). An Improved Lightweight PrivacyPreserving Authentication Scheme for SIP-Based-VoIP Using Smart Card. Anchor Academic Publishing. Retrieved from http://jankp.com/downloads/15-My\%20Book.pdf

[20] King, M. B., \& Newmann, F. M. (2001). 'Building School Capacity Through Professional Development: Conceptual and Empirical Considerations'. The International Journal of Educational Management, 15(2), 86-93.

[21] Kozma, R. (1994). Will media influence learning: Reframing the debate. Educational Technology Research and Development, 42(2), 7-19. Retrieved from http:// robertkozma.com/images/kozma_will_media_influence.pdf

[22] Little, J. W. (2001). 'Professional Development in Pursuit of School Reform'. In A. Lieberman \& L. Miller (Eds.), Teachers Caught in the Action: Professional development that matters. New York: Teachers College Press.

[23] Merrill, M. D. (2007). First principles of instruction: A synthesis. In R. A. Reiser \& J. V. Dempsey (Eds.), Trends and issues in instructional design and technology (2nd ed., pp. 6271). Upper Saddle River, NJ: Merrill/Prentice-Hall.

[24] Merrill, M. D. (2009). First principles of instruction. In C. M. Reigeluth \& A. A. Carr-Chellman (Eds.), Instructional-design theories and models: Building a common knowledge base (Vol. III, pp. 41-56). New York: Routledge.

[25] Sanyal, B. C., \& Martin, M. (2007). Quality assurance and the role of accreditation: An overview. In J. Tres \& Global University Network for Innovation (Eds.), Higher education in the world 2007: Accreditation for quality assurance: What is at stake? (2nd ed., pp. 3-17). New York, NY: Palgrave Macmillan.

[26] Stoll, L. (1999). 'Realizing our Potential: Understanding and Developing Capacity for Lasting Improvement'. School Effectiveness and School Improvement, 10(4), 503-532.

[27] Vail, J. (1999). 'Insecure Times'. In J. Vail, J. Wheelock, \& M. Hill (Eds.), Insecure Times: Living with insecurity in contemporary society. New York: Routledge.

[28] Wineburg, S., \& Grossman, P. L. (Eds.). (2000). Interdisciplinary Curriculum: Challenges to Implementation. New York: Teachers College Press.

[29] Wylie, C. (1994). Self-Managing Schools in New Zealand: The Fifth Year. Wellington: New Zealand Council for Educational Research.

[30] Jan, S. U., \& Fazal, K. (2018). An Improved Forest Fire Alerting System Using Wireless Sensor Network. Advances in Networks, 6(1), 21-39, https://doi.org/ 10.11648/j.net.20180601.13. 
[31] Jan, S. U., \& Qayum, F. (2018). A Robust Authentication Scheme for Client-Server Architecture With Provable Security Analysis. Network and Communication Technologies, 3(1), 6.

[32] Jan, S. U. (2017). An Improved Lightweight Privacy
Preserving Authentication Scheme for SIP-Based-VoIP Using Smart Card. Anchor Academic Publishing.

[33] Ary, D., Jacobs, L. C., Irvine, C. K. S., \& Walker, D. (2018). Introduction to research in education. Cengage Learning.

\section{Biography}

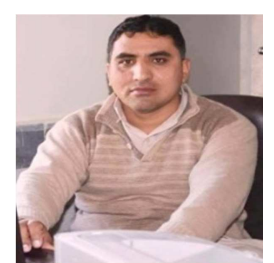

Saeed Ullah Jan received MPhil degree in Network Security from University of Malakand in 2016. He is working as a Lecturer in Computer Science at Higher Education, Achieves \& Libraries Department Govt of Khyber Pakhtunkhwa - Pakistan. His research interests include Computers \& Education, Information Security, VoIP, SIP Authentication, Cloud Computing, and Parallel Privacy-Preserving Authentication. He is also working as Coordinator for 09 BS Disciplines in Govt College Wari (Dir Upper) a far-flung remote area of the province where most of the Youngers have no access to Universities/institutions for Higher Education. Currently, he is $\mathrm{PhD}$ scholar in the Department of Computer Science \& IT - University of Malakand. 